\title{
Claroscuros de la inteligencia emocional iluminan la utopía
}

Luis Rodolfo Ibarra Rivas

Doctor en Educación

Universidad Autónoma de

Querétaro - México

libar@uaq.mx

https://orcid.org/0000-0003-1803-5319

Artículo de Reflexión

Recepción: 15 de abril de 2019

Aprobación: 18 de julio de 2019

https://doi.org/10.19053/22160159.v10.n25.2019.9282

\section{Resumen}

El objetivo de este trabajo de reflexión es enriquecer la teoría de la inteligencia emocional. Se contribuye a la alfabetización emocional con la distinción de: impulso, afecto, sentimiento, emoción y afectividad. Asimismo, se ilustran las implicaciones de tal distinción en la humanización. La metodología es de tipo complejo. Se presentan antecedentes de la inteligencia emocional: sus límites y potencialidades, tales como los claroscuros de la psicologización de la educación, la psicología cognitiva, los neuromitos y las teorías de la inteligencia emocional y de los sentimientos. El artículo exhorta a humanizar en aras de una utopía: una humanidad altruista.

Palabras clave: afectividad, educación del mañana, inteligencia, metodología compleja, utopía 


\section{The ups and downs of emotional intelligence enlighten utopia}

\section{Abstract}

The purpose of this study is to enrich emotional intelligence theory. A contribution is made to emotional literacy by distinguishing words like impulse, affection, feeling, emotion, and affectivity. Likewise, the implications of such distinction in humanization are depicted. The research method is of a complex nature. Background information about emotional intelligence are presented; its limitations and potentialities such as the ups and downs of the psychologization of education, cognitive psychology, neuromyths, and the theory of emotional intelligence and feelings. This article calls for humanization of an altruistic humanity in the pursuit of a utopia.

Keywords: affectivity, education of tomorrow, intelligence, complex method, utopia

\section{Les hauts et les bas de l'intelligence émotionnelle éclairent l'utopie}

\section{Résumé}

L'objectif de ce travail est d'enrichir la théorie de l'intelligence émotionnelle. Il contribue à l'alphabétisation émotionnelle au moyen de la distinction de mots tels que : impulsion, affection, sentiment, émotion, et affectivité. De même, il illustre les implications de telle distinction sur l'humanisation. La méthode de recherche est 
de nature complexe. Le contexte de l'intelligence émotionnelle est présenté ; ses limites et potentialités telles que les hauts et les bas de la psychologisation de l'éducation, la psychologie cognitive, les neuromythes, et les théories de l'intelligence émotionnelle et des sentiments. L'article appelle à l'humanisation d'une humanité altruiste dans l'intérêt d'une utopie.

Mots-clés : affectivité, l'enseignement de demain, méthode complexe, utopie

\section{Claro-escuros da inteligência emocional iluminam a utopia}

\section{Resumo}

O objetivo deste trabalho é enriquecer a teoria da inteligência emocional. Contribui-se à alfabetização emocional com a distinção de: impulso, afeto, sentimento, emoção e afetividade. Assim mesmo, ilustram-se as implicações de tal distinção na humanização. A metodologia é de tipo complexa. Apresentam-se antecedentes da inteligência emocional: seus limites e potencialidades, tais como os claro-escuros da psicologia da educação, a psicologia cognitiva, os neuromitos e as teorias da inteligência emocional e dos sentimentos. O artigo exorta a humanizar em aras de uma utopia: uma humanidade altruísta.

Palavras-chave: afetividade, educação de amanhã, inteligência, metodologia complexa, utopia 


\section{Introducción}

El propósito de este trabajo es esclarecer algunos claroscuros de la inteligencia emocional. Se analizan para preparar una forma de valorar y ejercer las prácticas educativas que guíe hacia una utopía con mayor precisión y trascendencia. Admitir teorías científicas es ventuoroso y es aventurado si se hace acríticamente; por ejemplo, algunas maestras y profesores movilizaron su tarea educativa en virtud de teorías que explican la inteligencia, ya sea considerándola múltiple (Gardner, 2015) o emocional (Goleman, 2016). Se trae a colación la teoría de las inteligencias múltiples, por ser un antecedente del tema central: la inteligencia emocional y sus implicaciones, por ejemplo, al buscar empleo (Nieto, Barrios \& Extremera, 2019).

Las teorías de las inteligencias múltiples y de la inteligencia emocional son un aporte a la educación. Como en cualquier contribución, conviene correr el velo de sus límites y potencialidades. Es iluso suponer que alguna teoría es omnicomprensiva o ajena a contradicciones y que, por lo mismo, no requiere apoyo de otros argumentos teóricos-empíricos. Un límite de las teorías psicológicas es que la mayoría centran su atención en el individuo. Es riesgoso confinar su estudio en él, porque se dejan un tanto de lado otros aspectos de lo humano: lo social, político, cultural, económico y ecológico: ċla inteligencia emocional es un proceso mental genético ajeno a procesos culturales o sociales?

Un peligro adicional es que algunos integrantes del gremio docente valoran las teorías psicológicas sin conocer suficientemente sus orígenes ni el contexto de su elaboración; por ejemplo, los afamados conceptos de Jean Piaget: procesos de asimilación, acomodación y construcción de nuevas estructuras (Zamudio \& Castorina, 2016); o de Ausubel, el quizá aún más popular término "aprendizaje significativo" (Monsalve \& Monsalve, 2015). Si se analizan las producciones derivadas de los autores fundadores de estas perspectivas teóricas, se advertirá más una aplicación de sus teorías, que una búsqueda de aquello que contribuye a explicarlas en su génesis.

Otro riesgo es que algunas psicologías deshistorizan al hombre, como el conductismo; incluso, no incorporan límites inherentes a 
estudios de género. Esta forma de comprender lo humano, en cierta forma abstracta, se traslada a la manera de valorar a la psicología misma; acaso, ¿se sabrá de qué partió Goleman (2016) para indagar la inteligencia emocional? ¿Qué respondió de forma innovadora con su teoría de la inteligencia emocional? Tal vez estas dudas no las aprecien quienes se jactan de procurar la inteligencia emocional.

Para muchos - entre ellos, quien escribe- la realidad se conoce de forma histórica, por sus procesos y estructuras de transformación: si se ignora la base de la que se parte y cómo se fue conformando, en buena medida se desconoce lo que se produjo, la teoría en cuestión. Sin comprenderla históricamente, se asimila de manera acrítica.

Es importante entender las condiciones contextuales de una aportación científica determinada - en este caso, la inteligencia emocional- para valorar en qué se apoyó su autor(a): de qué referencias se valió y qué contradicciones acontecieron en la base de su producción científica; qué criticó, qué límites encaró y cómo los enfrentó -método-; con su teoría, qué límites existentes superó de otras obras: qué conceptos y teorías formuló. Al tener respuestas a estas dudas, algunos argumentos serán recuperables, quizá otros no en su totalidad.

Ser crítico ante la producción científica exige hacer a un lado la forma de valorar maniqueísta: por ejemplo, bueno-malo, falsoverdad. Es preciso alejarse del maniqueísmo porque la ciencia no ofrece $L a$ verdad. Sí obsequia algo de conocimiento verdadero. $L a$ verdad es enaltecida por una orientación religiosa. El conocimiento verdadero, el que tiene mayor o menor grado de objetividad, interesa a los científicos. Es necesario admitir que toda teoría científica ofrece algo de verdadero. No postula La verdad total e inobjetable.

Es plausible reconocer la importancia de educar lo que Goleman denominó emociones. Lo es porque educar consiste en el acto de transmitir ideas, prácticas y sentimientos. El ser humano es pensante, actuante y sintiente; cada uno de esos ámbitos requiere del concurso de educadores. Goleman ofreció formas de reaccionar ante las emociones para educar a quien las experimenta. Solo es necesario adelantar que no distinguió de manera fehaciente emoción y sentimiento. Heller (1993) sí los distinguió, aunque no fue tan precisa al expresar cómo educar la afectividad. 
La inteligencia emocional es un atrayente objeto de estudio por su incidencia en la educación. Aquí se ilustrarán algunos de sus claroscuros. Para tal fin, primero se expresa qué guió esta investigación: la metodología. Después se contextualiza la inteligencia emocional dentro de un proceso que la subsume: la psicologízación de las prácticas educativas. Seguirá un bosquejo de la psicología cognitiva ya que contribuyó a postular la teoría de las inteligencias múltiples. Enseguida se señalarán nexos entre neuromitos y la teoría de las inteligencias múltiples. Continúa un apartado sobre límites y aportes de la teoría de la inteligencia emocional. El trabajo después muestra cómo complementar la teoría de las inteligencias múltiples: ofrece argumentos para distinguir impulso, afecto, sentimiento orientativo y emociones. Termina invitando a reflexionar sobre qué incorporar en las prácticas educativas, para propiciar una afectividad que contribuya al logro de fines trascendentes.

\section{Metodología}

Este apartado contiene principios que guiaron la indagación de algunos claroscuros de la inteligencia emocional. Claroscuros es una expresión que, para fines de este trabajo, representa la contradicción; abajo se explica, así como otros principios.

\section{Contradicción}

No es una palabra para descalificar la realidad; hay quien opina con enfado: “iEres muy contradictorio!”. Es un concepto que contribuye a comprender el objeto a estudiar. Se entiende porque permite valorar lo que orienta a que exista y avance - evolución, progreso o desarrollo- y, simultáneamente, lo que contiene o desvía el movimiento en favor de la historia. La historia, para unos, es evolución; otros la admiten como resultado de la lucha de opuestos. Cualquiera que sea el caso, las contradicciones de la realidad exhiben aquello que tiende a favorecer su avance y lo que lo entorpece o dificulta: los claroscuros. La inteligencia emocional es contradictoria: es un avance $y$, si no se supera, es una barrera.

\section{La realidad es histórica}

La realidad está en cierta quietud y movimiento, sea que se estime evolución, sea producto de lucha de contrarios. Considerar 
los procesos psicológicos, sociológicos, políticos, económicos, técnicos, educativos, en suma, antropológicos, sin una perspectiva histórica, simplifica y arrastra a equívocos o, al menos, a reducciones y abstracciones. Lo real es producto temporal de un haz de procesos: para conocer mejor la inteligencia emocional conviene valorar sus antecedentes, algunos sucesos que al entrecruzarse condujeron a producir esa teoría.

\section{Inteligencia ciega (Morin, 1998)}

El sentido común lleva a contraponer la realidad con antinomias, dualidades o pares antitéticos: moderno-tradicional, individuosociedad, innato-adquirido, La verdad-falso, etcétera. También la inteligencia es ciega porque aísla o abstrae los procesos humanos; no los valora en la complejidad de sus interrelaciones: físicas, biológicas y antropológicas. La inteligencia emocional se explica de manera compleja considerando, al menos, aquello que es genético y adquirido, individual y social, biológico-natural y cultural, duradero y circunstancial.

\section{Relatividad}

El sentido común la adoptó y vulgarizó con un dicho inaceptable: "todo es relativo"; al admitirse se acepta un absoluto: "todo es...". En lugar de tal pamplina, el aporte de Einstein lleva a valorar las enmarañadas relaciones existentes entre observador, realidad y tiempo: ante un mismo fenómeno, lo que se diga a propósito de él es diferente según sea el enfoque de cada observador y el momento de percibir y pensar; habrá argumentos verosímiles y otros distantes de objetivar lo que es motivo de investigación. La inteligencia emocional será potenciada si comprende y valora las diferencias de enfoques, lo relativo y circunstancial.

\section{Incertidumbre}

Este es un principio de la teoría cuántica. Es necesario reconocer que -por más que un observador se afane en comprender una realidad cuántica en su totalidad- es imposible que advierta, al mismo tiempo, la posición y el movimiento de una partícula. De lo real unas cosas se conocen, a la par que otras están vedadas al observador. Por ejemplo, al entender lo psicológico de la conducta 
estudiantil, en un fugaz momento, es imposible en ese instante comprender sus nexos con lo social o político. Únicamente después del suceso algunas relaciones se valorarán y otras quedarán veladas. La inteligencia emocional requiere prudencia y tacto ante lo incierto.

\section{Incompletud del conocimiento}

Está vinculada con los principios previos: la realidad se conoce en varias áreas -física, biológica y antropológica-, niveles macro, medio y micro-, temporalidades-coyuntura, presente, larga duración-, según fines -describir, interpretar, hacer leyes, transformar o criticar-. Aquí se siguieron los fines conceptuales de describir-fenomenología-, interpretar-explicar-hermenéutica-, criticar - mostrar contradicciones- y solo pálidamente prescribir -interés pedagógico-. Conocer es un proceso inconcluso. La inteligencia emocional no debe ser soberbia ni sobrestimar sus juicios como si fueran la última palabra.

\section{Integrar}

Es inexistente un estudio total, de la realidad total. No obstante, sí es necesario integrar aquello que sea posible y determinante del fenómeno estudiado: hacer configuraciones o racimos de conceptos (Garza, 2018) o redes de relaciones entre teorías para acrecentar el conocimiento de la realidad; aunque con humildad hay que tolerar que no será conocida de manera absoluta. En esta aportación se ofrecen algunos elementos para conocer la inteligencia emocional y sus claroscuros. Se concluye con este principio: unir lo disperso y complejizar lo que de suyo es intrincado: lo real.

\section{Psicologización de la educación}

Esta tendencia se caracteriza porque existe el predominio de la psicología sobre la filosofía, la pedagogía y las ciencias de la educación (Hanhela, 2014; Ocampo, 2019; Prieto, 2018). Hay un dominio psicológico porque los procesos educativos, valga la redundancia, casi solo se valoran con argumentos psicológicos.

La psicologización tuvo uno de sus inicios con Johann Friedrich Herbart -1776-1841-, filósofo, pedagogo y psicólogo alemán. Fue un precursor del interés por dar una base científica a la educación: 
la psicológica (Ortiz, 2017). Actualmente pocos educadores saben de sus ofertas psicológicas y pedagógicas. En sus inicios, la psicologización de la educación no se alejó de la postura pedagógica, de imaginar y postular un deber ser.

La psicologización de procesos educativos comenzó hace más de dos siglos con la mira de dar una base científica a la tarea educativa. La oferta teórica de las psicologías no es trivial, es formidable. Quizás algunas maestras y maestros ignoren su amplitud y complejidad; así como, desconozcan sus límites al educar al casi solo circunscribirse a:

a) Explicar cómo aprender: reducir al acto educativo al proceso mental primario de aprender, sin ocuparse de otros procesos mentales superiores como pensar, reflexionar o actuar con inteligencia.

b) No estipular para qué o por qué educar: no dotar de sentido a educar: no ofrecer finalidades plausibles ni trascendentes.

c) Sobreexaltar al individualismo: el hombre tiene sentido en sí mismo.

d) No criticar al hedonismo: admitir sin reparo alguno que el comportamiento humano se oriente a la satisfacción o al placer, y que se oponga a luchar o al desasosiego.

e) Elegir una teoría psicológica y desdeñar al resto: en ocasiones, las teorías suelen ser complementarias; por ejemplo, es indeclinable aceptar los actos inconscientes propuestos por Freud y, al mismo tiempo, es necesario saber cómo encarar los afectos que devienen de actos fallidos.

f) La psicopolítica (Han, 2017): es otra crítica a la psicologización al educar: quien está sometido no se percata de ser dominado, las relaciones psicológicas que lo sujetan son inasequibles para él: se juzga libre; no advierte el poderío sutil y encantador. Es seducido y no se le impone mutismo. Contrariamente, se le exige intervenir e informar; se le obsequian facilidades: no hay decisión libre, existe un sucedáneo: libre elección de ofertas preestablecidas (Han, 2017, pp. 28-29). 
Además de esos límites, es necesario valorar que la escuela y la educación son un medio para humanizar (Comenio, 1982, p. 37). Humanizar es un proceso que inició con la especie humana y, hasta la fecha, no concluye. En una escuela o salón de clases, no solo se educa ni se aprende: la colectividad docente y la estudiantil no están constituidas por máquinas de enseñar ni aprender. Estudiantes, profesoras y maestros también juegan y socializan (Ibarra, 2017a).

La noble tarea de humanizar demanda el más diverso y abundante apoyo teórico y práctico. Los aportes de las psicologías son una magnífica ayuda. Psicologizar la educación generó un cariz científico: contribuye a comprender, objetivamente, la conducta estudiantil y del gremio docente; así mismo, ofrece guías para actuar; por ejemplo, gracias a los aportes de la teoría de la inteligencia emocional.

\section{Psicología cognitiva}

En Estados Unidos de América, luego del apogeo del conductismo, hubo una significativa respuesta a un cimiento del psicólogo Skinner: la llamada caja negra. Para el conductismo lo que acontece en la mente o, dicho de otra forma, en el cerebro, es un fenómeno no observable y, en tal virtud, no es susceptible de investigarse. El pionero de una nueva forma de comprender los procesos cognitivos fue el norteamericano Ulric Neisser (1999). De acuerdo con autores como Sánchez (2017), él ideó un nuevo enfoque para el estudio de los procesos mentales. Uno de sus cimientos fue gracias a una metáfora: equiparó los procesos mentales y la mente con lo que realiza un sistema de cómputo: recibe información, la selecciona, organiza, transforma, almacena y utiliza.

Neisser estudió los procesos mentales que suceden al conocer de forma interdisciplinar y se apoyó en varias teorías (Solís, 2014):

a) Matemáticas de la comunicación: considerar que, en última instancia, la información que se procesa son símbolos o abstracciones.

b) Lingüística: incluir lo performativo o creativo de algunos vocablos.

c) Detección de señales: percibir un estímulo depende de su intensidad y del estado psicológico de quien lo advierte; se percibe si su intensidad sobresale del ruido ambiental. 
d) Sistemas: valorar las condiciones en que acontecen los procesos mentales, ya sean trasformaciones o sistemas.

e) Información: incluirla fue un giro sorpresivo.

Para estetrabajo cobra especial interés la teoría delainformación. Esta se considera en los procesos mentales o computacionales como:

a) bit: unidad mínima de información, en sí misma carece de sentido y solo acompañada de otra información es procesable;

b) memoria: son las estructuras de la realidad almacenadas en archivos, organizadas por pautas o por ser información convergente, incluso que difiere, solo que coincide en un algo;

c) programa: el cúmulo de información lleva a ejecutar -o noalguna decisión;

d) ruido: la información que se recibe no es procesable ni por la memoria ni por los programas disponibles (Neisser, 1999, pp. 17-19).

Es importante considerar las vertientes que tiene la información porque la inteligencia emocional reacciona sobre aquello que la estimula, la información: si es un bit, no le dará mayor importancia; si es ruido, tal vez lo evite; si es programa, lo impulsará a actuar; si es memoria, la almacena. La teoría de la información genera cuestionamientos al gremio docente: quizá la mayoría de sus miembros estimen que sus estudiantes comprendan la información sin mayor dificultad. Tal vez no valoren que sus estudiantes pueden confundir la información docente: no es raro que algunas maestras y profesores no comprendan que sus alumnos no los comprendan.

Un ejemplo de dificultades en la información docente es: si el estado psicológico del joven o señorita es de mucho tedio, seguramente no solo no comprenderá la información docente, quizá la menosprecie y considere un bit. En casos como este, sucede lo que el sentido común afirma: "parece entrar por un oído y salir por el otro". Transitar a procesos mentales secundarios - del pensamiento y acción- precisa atención focalizada y selectiva del estudiante sobre la información docente. Además, es necesario considerar otros requerimientos. 
Por muy atento que esté un o una estudiante, la información no la procesa de manera automática. En ocasiones, lo que emita el profesor o maestra no será realmente percibido: su intensidad o su importancia no sobresale del ruido ambiental del aula o de la escuela. Las circunstancias en las que se den los procesos mentales superiores no son de naturaleza menor: contribuyen a crear una atmósfera propicia para percibir y procesar la información; ya sea programa -hacer algo como resolver problemas de diversa índoleo memoria - almacenar la información-.

Los procesos mentales, al descifrar la información, son realizados por un individuo. Tal proceso no se da en el vacío ni en condiciones controladas de laboratorio. Los procesos mentales individuales son circunstanciales: relativos a condiciones temporales, espaciales, individuales y colectivas. El ambiente del salón de clases puede contribuir a pensar-reflexionar-actuar, así como propiciar una atención no selectiva ni focalizada; un sentido común docente asegura al respecto: "los jóvenes están dispersos". El énfasis de Neisser fue en los procesos individuales, casi no se ocupó de lo social al conocer.

Neisser (1999) gastó más tinta y papel en esclarecer los procesos mentales visuales, auditivos y de atención. Sobre esos aspectos escribió diez capítulos -289 páginas-. Sobre los procesos mentales superiores de memoria y pensamiento solo escribió uno -30 páginas-. En su libro enlazó la inteligencia solo con referencia a "modelos de computadoras de cognición". No desarrolló el concepto de inteligencia ni mucho menos lo que luego Gardner escribió: el modelo de las siete inteligencias. No obstante, sí sirvió de base para estimular la imaginación de Gardner.

Neisser se declaró constructivista: las estructuras de la información que se almacenan en la memoria no son copia de los estímulos que se advierten; son un producto temporal que deviene del proceso de construir las nuevas estructuras de la información sobre la base de las huellas de construcciones previas.

De acuerdo con Neisser (1999, pp. 325-327), la información que se almacena como memoria - en forma de estructuras- se organiza colocándola en un sistema de archivos. En cada archivo se sitúan memorias específicas. Este sistema de archivos da lugar 
a una orientación generalizada ante la realidad, debido a los sistemas organizados de información almacenada que contienen. La organización sistémica de la memoria y su correlato, la orientación generalizada ante la realidad, son comprensibles si se admite que sus partes tienen interrelaciones regulares y controladoras: son un marco de fondo, un marco de referencia espacial, temporal y conceptual.

En la diversidad de acciones individuales, ora al percibir, ora al tener una atención focalizada y selectiva, ora al procesar la información para recordar o pensar, el marco referencial puede generar una atención muy vivaz, o bien llevar a no atender la nueva información. Conocer no se hace en abstracto. Es un proceso complejo: con cierto grado de libertad; es individual selectivo y focalizado; coexiste el deseo de conocer con las condiciones espaciotemporales y simbólicas y con la orientación generalizada.

La experiencia de la persona es un sistema compuesto por los subsistemas de memorias, programas y la orientación generalizada la que dirige con una cierta tendencia-. La forma en queinteractúan los tres elementos no siempre es advertida, ya que el marco referencial es un sello de fondo. Solo si se tiene la capacidad y el deseo de reflexionar sobre el sistema que decide sin que medie una decisión, cabalmente consciente, se reorientará la forma de guiarse ante la realidad: ni la historia ni el origen es destino. El ser humano es educable, aunque no totalmente a voluntad del educador o educadora. Cuando el gremio docente sepa sus limitaciones, sabrá cómo encararlas.

\section{Teoría de las inteligencias múltiples y neuromitos}

Esta teoría es importante porque es un antecedente de la teoría de la inteligencia emocional. Será brevemente analizada porque otros la denominaron como neuromito (Fuentes \& Risso, 2015; Varas-Genestier \& Ferreira, 2017). Un neuromito es, por ejemplo, asumir que el predominio de un hemisferio cerebral -izquierdo o derecho- explica diferencias individuales entre aprendices. Sin duda el cerebro se compone de redes neuronales y áreas funcionales que interactúan entre sí: hemisferios izquierdo y derecho. Cada uno se especializa más en ciertas actividades. Tal hallazgo no justifica mitos tales como: "las mujeres tienen más desarrollado el lado derecho del cerebro" o "él es menos desarrollado del lado izquierdo". 
La información dada por las neurociencias sí especifica que cada hemisferio cerebral -derecho e izquierdo-procesa de manera diferente la información; no obstante, es imprescindible considerar la diversidad de formas en las que los dos hemisferios interactúan y los mecanismos biológicos que soportan esa interacción. De manera opuesta al neuromito, es mejor integrar las formas de procesar la información, en lugar de enfatizar en centrar el procesamiento de información en un solo tipo de relación, conforme se califique a una persona (Fuentes \& Risso, 2015, p. 2).

Es provechoso considerar que la teoría de las inteligencias múltiples, llevadas a la educación, merece el adjetivo de neuromito porque es una concepción errónea del aprendizaje: carece de relaciones o argumentos entre investigaciones procedentes de las ciencias neurocognitivas y la educación (Fuentes \& Risso, 2015). Tiene origen en una idea científica que, gradualmente, se convierte en un concepto deformado, que solo se mantiene y difunde gracias al aspecto de autenticidad primitiva (Paterno, 2014, p. 124). También es un neuromito porque hay una enorme dificultad de comunicar y aplicar, al educar, resultados de la neurociencia, debido a la carencia de un lenguaje común, interdisciplinar, entre educación y estudios neurocerebrales (Varas-Genestier \& Ferreira, 2017, p. 342).

Tal manera de trasladar resultados científicos a la educación es infundada: es inadmisible valorar a alguien con más desarrollo de alguna "inteligencia", sin evidencia empírica -dada por estudios neurológicos- que lo confirmen: des posible que las técnicas de electroencefalografía y neuroimagen midan "el mayor grado de desarrollo de una inteligencia"? Es improbable porque la información recabada es sobre la actividad neuronal al ejecutar tareas cognitivas específicas.

Los neuromitos en educación -derivados de investigaciones científicas neurocerebrales- adolecen de otra seria limitante: los estudios de electroencefalografía y neuroimagen se realizan en condiciones controladas de laboratorio, de manera similar al ambiente regulado en las investigaciones de Skinner con pichones. Bajo esas condiciones, los resultados de la neurociencia son objetivos. Es un despropósito trasladar al aula lo obtenido en condiciones sistematizadas. Lo es porque en el salón de clases priva la incertidumbre. 
Paradójicamente, es indefendible suponer que los procesos educativos no tengan bases neurológicas: no valorar o pretender borrar de un plumazo la oferta teórica de las neurociencias en la educación es un despropósito; el sentido común docente admite que el ser humano es bio-psico-social. La sensatez estriba en saber qué emplear y qué valorar con reservas.

No es del todo desdeñable la teoría de las inteligencias múltiples: fue un soporte de la inteligencia emocional. Tampoco se puede despreciar, en forma definitiva, porque inspira la ventaja de diversificar la comunicación, la información, educativa. Incita a evitar el monopolio de la palabra oral o escrita, impedir el excesivo uso de las imágenes o el continuo imperio del juego al educar.

En 1983 Gardner (2015) escribió su teoría de las inteligencias múltiples: auditiva-musical, kinestésica-corporal, visual-espacial, verbal-lingüística, lógico-matemática, intrapersonal-interpersonal y naturista. Luego Mayer, Dipaolo y Salovey (1990) restringieron su interés en la inteligencia emocional; partieron de la inteligencia intrapersonal e interpersonal de Gardner. En 1995 Goleman publicó su libro La inteligencia emocional. Contribuyó así a difundir la importancia de lo afectivo al educar.

En el siglo XXI, en muchos centros educativos y empresariales, es usual expresar con cierto aire de suficiencia: "maneja tus sentimientos conforme a la inteligencia emocional”. Quienes exaltan tal oferta encontrarán aquí elementos para apoyar sus juicios. También advertirán límites que es necesario subsanar.

\section{Inteligencia emocional}

Como ya se expresó, esta teoría ofrece claroscuros. Para valorarla es provechoso enmarcarla dentro de los procesos que experimentó. El primero es el denominado psicologización de la educación. Hoy -2019- existen en Google más de 24 millones de sitios que aluden a los indicadores inteligencia emocional. Es innegable que Goleman contribuyó al dominio común de los términos inteligencia emocional; se puede decir que forman parte de un sentido común actual. Tal resultado es benéfico: los resultados de la ciencia llegan al público no especializado. También hay deficiencias y limitantes: se vanaliza lo complejo del actuar humano. 
Una búsqueda más restringida, en Google Académico, muestra que existen 16100 sitios registrados de 2015 hasta abril del 2019. Son artículos que tratan algo sobre "inteligencia emocional". En la Red de Revistas Científicas de América Latina y el Caribe, España y Portugal -Redalyc- hay 104 785. Los temas de esos artículos son diversos; existen para: consumidores de cocaína, empresas, mejorar la práctica docente, comprender a los adolescentes o actores de educación superior, valorar alumnos superdotados, intervenir en circunstancias de violencia de género, alentar la resiliencia, liderazgo, educación física y sigue una larga enumeración de temas. En buscadores de librerías o en el portal de Amazon, hay más de 120 libros sobre inteligencia emocional; van desde libros dirigidos a la escuela, padres, empresas, autoayuda, incluso para el uso del tarot.

Esos datos numéricos permiten admitir que la inteligencia emocional se difundió de manera profusa: se comunicó o se hizo de un cierto dominio común, ya sea científico o de gente no especializada en áreas de la ciencia de la psicología. Ese mérito, inicialmente, es de Goleman. Luego es atribuible a quienes encontraron en sus teorías soporte para entender temas específicos. Según informes de autores, una cantidad razonable de discursos y prácticas educativas son liderados, en la actualidad, por teorías provenientes del campo de la psicología: inteligencia emocional (Prieto, 2018).

Goleman (2016) destacó que la mente emocional y racional operan, por lo general, en ajustada armonía; no obstante, al ser semi-independientes tienen cierta autonomía, sobre todo "cuando aparecen las pasiones, la balanza se inclina: es la mente emocional la que domina y aplasta la mente racional" (pp. 27-28).

Goya advirtió el nexo razón-emoción con el título de una de sus litografías: "Los sueños de la razón producen monstruos". El sueño de la razón tiene varios sentidos: los sueños-deseos-pasiones de la razón generan monstruosidades, por ejemplo, el inadmisible deseo de exterminio de judíos y otras etnias llevó a humanos a realizar atrocidades. Otra forma de entender el "sueño" de la razón es cuando efectivamente se duerme y uno queda obnubilado, como cuando al embriagarse ya no se controla la acción humana por la razón. Uno más es lo acontecido al mismo Goya: su pasión por criticar la razón proveniente de la Ilustración lo llevó a crear una obra de arte con tintes de espanto que mueve a razonar. Razón y emoción son un 
par dialógico: uno requiere del otro para existir. Razón y afectividad también necesitan de la práctica humana.

Es posible que profesores y maestras, especialmente de educación superior (Gilar, Pozo \& Castejón, 2019), valoren sus prácticas educativas siguiendo la impronta de la relación social de tipo moderna: imperio de la racionalidad orientada a fines (Cruz, 2017). Lo que Weber (2004) llamó "la jaula de la razón" inclina a no establecer relaciones orientadas a valores, menos a la tradición y aún menos a lo afectivo. En el contexto de la propagación mundial de la forma de relación social que persigue fines, indudablemente, es plausible que Goleman ponderara los nexos emoción-educación.

Otro aporte de la teoría de la inteligencia emocional consiste en objetivar la relación razón y afectividad (Rueda \& Filella, 2016, pp. 214-217):

1. Conciencia emocional. Cobrar conciencia y comprender: las emociones propias y de los demás; nominarlas; ponderar los vínculos entre emoción - sentimientos-, cognición -ideas-y conducta - prácticas-.

2. Regulación emocional. Ofrecer una expresión emocional adecuada al regular las emociones, tener la habilidad de encarar retos y autogenerar emociones positivas.

3. Autonomía emocional. Poseer loables formas de autoestima, automotivación, autoeficacia y resiliencia; basadas en la responsabilidad social, en un análisis crítico de las normas y en una actitud altruista.

4. Competencia socioemocional. Establecer relaciones sociales admirables, gracias al respeto y seguimiento de habilidades sociales: respeto, escuchar empáticamente, comunicarse expresivamente con miras a equilibrar agresividad y ternura, contribuir a prevenir y solucionar conflictos, y gestionar circunstancias emocionales adversas.

5. Competencias para la vida y el bienestar. Organizar la vida en su conjunto -familiar, social, laboral, de ocio- al fijar metas adaptables y decidir valorando los recursos materiales y humanos, para contribuir al bienestar personal y ciudadano. 
La objetivación de los complejos vínculos razón-emociónpráctica es una valiosa muestra de lo interdisciplinar que Neisser propició, con su psicología cognitiva. En la teoría de la inteligencia emocional, Goleman sugirió teorías: sociales -formas de relación social-, políticas - manejo del poder-, éticas - diferencias entre lo deseable y reprochable-, estéticas - apreciar lo bello y apartarse de lo ridículo o grotesco-; económicas - valoración tangible del éxito-, tecnológicas - apoyo de recursos materiales-y psicológicas -cómo procesar la información-. iMenuda tarea que Goleman planteó al gremio docente: ser un individuo maravilloso! En los plausibles deseos de los teóricos de la inteligencia emocional, existe ese tremendo reto. Y hay uno más: nominar las emociones.

Nominar es una seria dificultad. Ni Goleman ni la mayoría de sus discípulos diferenciaron emoción, sentimiento y afecto. Él escribió: "utilizo el término emoción para referirme a un sentimiento y sus pensamientos característicos, a estados psicológicos y biológicos, y a una variedad de tendencias a actuar" (2016, p. 331).

Si se admite el llamado a la alfabetización emocional, es imperioso distinguir entre formas humanas que reciben distintos nombres: impulso, afecto, sentimiento y emoción. Es irrecusable porque nominar al objeto conduce a una forma de relación de él con su entorno y de él con quien lo observa. Por ejemplo: ¿̇cómo admitir que se nominen de manera indiscriminada catetos e hipotenusa? Cada lado de un triángulo rectángulo establece un cierto tipo de relaciones que lo distinguen de los demás; de manera similar, ¿̇cómo aceptar que al hueso llamado radio se le diga cúbito o a la inversa?

\section{Teoría de la afectividad}

El libro Teoría de los sentimientos (Heller, 1993), a pesar del laxo nombre sentimientos, ofrece recursos teóricos para comprender un fenómeno complejo: la afectividad. Esta es más que impulsos, afectos, sentimientos y emociones. Es un sistema que como postuló Neisser- orienta la vida del ser humano. Sigue dos principales tendencias: altruista, propia del ser humano individual, de quien se avoca a trabajar y vivir en provecho del género humano; y egoísta: propia del ser humano particular que se interesa por $s u$ familia, su casa, su trabajo, en general se ocupa de sus cosas (Heller, 
1977). El recurso teórico tendencia impide aceptar que alguien solo sea de una manera -individual o particular-; más bien, las personas se orientan más a atender sus necesidades -egoísmo- o, bien, más a vivir y producir en beneficio de toda la humanidad altruismo-.

La afectividad también es un sistema porque lo componen de manera compleja varios subsistemas: impulsos, afectos, sentimientos y emociones. Es complejo porque las relaciones entre sus componentes no son de una única manera; incluso, en algunas circunstancias se confunden. No obstante, para fines de análisis sí son separables, a saber (Ibarra, 2017b):

\section{Impulso}

Los impulsos son señales que provienen del organismo humano y exigen satisfacer alguna necesidad. Solo los percibe quien los vive. Preservan biológicamente la especie. Llevan a atender lo vital: comer, evitar dolor, beber, etcétera. Los impulsos son la herencia muda de la especie.

\section{Afectos}

Los impulsos llevan a satisfacer necesidades vitales y luego de un tiempo se convierten en afectos. Su diferencia estriba en que los afectos son movidos por un estímulo externo. Los afectos son expresivos, pertenecen a toda la especie humana; por ejemplo, el mohín facial de coraje es comprensible en casi todo lugar. Los afectos se limitan, al apartar al objeto que lo suscita. Mejor aún, si se nomina al afecto - asco, coraje, miedo, burla, tedio, por ejemploque se siente y se platica sobre aquello que lo suscita: si se descubre la fantasía que está atrás de lo que provoca al afecto; así, se piensa y reflexiona sobre el afecto, sus mecanismos e implicaciones - asco por una cucaracha, por caso-. Es preciso educar a quien expresa afectos, porque suscitan contagio grupal: si el maestro o maestra expresa afectos - por ejemplo, vergüenza o rabia-, sus estudiantes probablemente también. Tal vez se ignora que los afectos surgen casi sin mediar la voluntad ni el pensamiento. Los afectos son idiosincráticos: en algunos lugares-culturas-tiempo comen insectos, en otros, provocan repudio. 


\section{Sentimientos orientativos}

Parecen naturales, pero son producto de la experiencia, educación, socialización y juego: dotan de poderío predictivo. Cuando los jóvenes están educándose, su inexperiencia los conduce a guiarse más por prejuicios. Existen adultos sin muchas experiencias que hacen una y otra vez lo mismo. Los sentimientos orientativos contribuyen a decidir, al afirmar o negar; no son instintivos; las objetivaciones sociales los moldean al almacenar sentimientos, prácticas y conocimientos, al construir programas. Los bebés desconocen cómo conducirse; niños y adultos sí saben. Son un sentido práctico que guía la afectividad, los pensamientos y acciones; tienen auto-ignición. Forman parte del marco referencial, espacial, temporal y conceptual que orienta a la persona. Son impulsados por el sentido común, el cual no es tan común, pues varía según espacio, tiempo y grupo social. Los sentimientos orientativos guían a:

\section{Trabajar}

Estos sentimientos ayudan a apropiarse de la destreza de un oficio: se hace lo que se debe, sin necesidad de tanto razonar. Evitan que el azar prive. Es un sentimiento de posibilidad: "siento que por aquí es", "siento que, si hago esto, la máquina funcionará", "sospecho que, si no me apuro, habrá problemas".

\section{Pensar}

Los sentimientos orientativos difícilmente se abstraen del proceso cognoscitivo; casi siempre lo acompañan. Contienen o propician procesos cognitivos. Reconocerlos ayuda a comprender nuestra forma de conjeturar: a veces hay suficiente experiencia para guiar adecuadamente al conocer, a veces no tanta: se siguen mitos. Acompañan reflexiones: "estimo que es así", "temo que es erróneo", "siento que esto no encaja". Quien los despliega exitosamente es denominado como atinado en sus reflexiones.

\section{Contactos interpersonales}

Los sentimientos orientativos tienen varias facetas. A una la sabiduría popular la llama tacto. Quien carece de tacto es un pesado o aguafiestas. Personas sin tacto provocan afectos indeseables. El tacto es más requerido entre más relaciones se tienen con otros. 
Es un punto de partida de una relación. Puede ofrecer información errónea: la primera impresión luego debe ser modificada.

\section{Prudencia}

Es el acierto de hacer, decir o valorar lo plausible en el momento, lugar, forma, sentido, intensidad y por el motivo adecuado.

\section{Buen gusto}

La persona requiere orientar su relación con los demás de forma agradable. Existen gustos refinados; hay otros que de tan exquisitos son chocantes, para algunos grupos sociales.

\section{Relaciones}

Son sentimientos de amor-odio, simpatía-antipatía, atracciónaversión. Orientan al elegir con quien relacionarse de manera estrecha. Por muy regulada que esté una sociedad, o un grupo social, se necesita una guía que oriente a quien amar o repeler; esa guía son sentimientos: disposiciones que llevan a diferenciar amor y amistad, por ejemplo. Su fuente también es la experiencia y conocimientos acerca de lo deseable y reprochable.

\section{Emoción}

Es una constelación de sentimientos. Las emociones están vinculadas con lo temporal y social; es idiosincrática. Gracias a ellas es factible la coexistencia social, ya que subliman y regulan sentimientos y afectos. Son circunstanciales: ante un algo, inopinadamente, se derraman lágrimas y, simultáneamente, se es muy feliz; se experimenta el deseo de ser generoso y melancolía ante sucesos gratos, que llevan a la esperanza de un mundo mejor y el recelo por lo incierto. La emoción es un racimo de sentimientos, no todos coincidentes. La emoción tiene dos tendencias: gozo y dolor espiritual: el dolor se comprende porque el ser humano padece la imposibilidad de que su ego o personalidad crezca; mientras que el gozo es por la gratísima satisfacción de un ego fortalecido y más valioso (Heller, 1993, pp. 119-132; Ibarra, 2017b, p. 14).

Diferenciar, reconocer y explicitar las emociones agranda el bienestar y el crecimiento humano; no reconocerlas puede 
empobrecer y alienar. La emoción aliena si provoca algo desfavorable para el género humano - cuando es propia de un hombre particular, cuando él o ella no son sensibles al daño que provocan-. En cambio, es benéfica para la humanidad cuando ofrece bienes que la mejoran.

\section{Conclusiones}

Es provechoso considerar lo incompleto de la ciencia y estar atentos a los mitos. Goleman demandó la alfabetización emocional. Es plausible tal exigencia. Él no resuelve cabalmente la teoría de la inteligencia emocional; legó la tarea de distinguir impulso, afecto, sentimiento y emoción. Es imperioso saber qué es cada uno; asimismo, es necesario conocer cómo se relacionan entre sí. Una metáfora para ilustrar esto es: las letras del alfabeto forman sílabas, que forman palabras, que forman párrafos, y estos, un discurso. El discurso se orienta por letras, sílabas, palabras y párrafos en un todo organizado y con coherencia. Como el discurso, el sistema mayor es la afectividad, que está formada por el impulso, equiparable a la letra; sílabas a afectos, sentimientos a palabras y emociones al párrafo. Un ejemplo de la importancia de distinguirlos es que la educación tendrá una notable mejora si los sentimientos orientativos de tacto, buen gusto, prudencia o destreza suplieran afectos de coraje, miedo, burla o egoísmo.

Neisser explicó el actuar humano: tiene cierta cohesión y orientación gracias al marco referencial, espacial, temporal y conceptual. Este es un trasfondo; no se tiene plena conciencia de él. El ser humano se guía por ideas y prácticas, también por la afectividad. La orientación generalizada ante la realidad, la forma de ser, es comprensible si se admite que sus partes tienen interrelaciones regulares y controladoras: la afectividad y el marco referencial las orientan; ambos son un fondo poco visible que impulsa a decidir con una tendencia al egoísmo o al altruismo, a ser un humano particular o individual. Educar y humanizar son más eficientes y dignos al reconocer que algo guía las decisiones, sin que se tenga plena conciencia de qué es. Si se conversa sobre lo que conduce al actuar, sin tener conciencia de ello, podrá ser para bien de la humanidad - al reestructurar al marco referencial y la afectividad inherente a él- al advertir cuando se actúa con una tendencia altruista y cuando con otra egoísta. 
Es necesario conocer los sistemas mayores para no afanarse en batallar con una letra-afecto sin valorar su nexo con el discursoorientación generalizada: afectividad y marco referencial. Estos son dirigidos por un sistema aún mayor, las tendencias de afanarse en provecho propio o, mejor, en beneficio de la humanidad. Un mohín de ira muestra afecto, quien lo hizo puede valorarlo banal, lo equipara a un bit, aunque quizá pruebe egoísmo.

Debe admitirse lo circunstancial, incierto, incompleto y verdadero del conocimiento de la contradictoria e histórica realidad. Un ser humano, estudiante o maestro, no es el cartabón que le atribuyen: nerd o mal maestro, por ejemplo. Origen no es destino. Educandos, maestras y profesores son educables. El proceso de humanizar no tiene fin. Sí tiene finalidad: contribuir a formar para el altruismo.

La humanización se beneficia al usar adecuadamente la relación diversa: educativa, socialización o juego. Favorece al formar de manera admirable a un diestro ingeniero, un prudente político, un ser con tacto, un talentoso científico que guía sus investigaciones con tino. Los claroscuros de la inteligencia emocional iluminan otro derrotero: la utopía, la humanidad altruista.

\section{Referencias}

Comenio, J. (1982). Didáctica Magna. México: Porrúa.

Cruz de la, P. (2017). Imperio de la racionalidad con arreglo a fines: análisis desde la actualidad y vigencia de las categorías y conceptos de Carl Schmitt. Revista Internacional de Pensamiento Político, 12, 369392. Recuperado de http://bit.ly/2LboroL

Fuentes, A., \& Risso, A. (2015). Evaluación de conocimientos y actitudes sobre neuromitos en futuros/as maestros/as. Revista de Estudios $e$ Investigación en Psicología y Educación, (06), 193-198. https://doi.org/10.17979/reipe.2015.0.06.530

Gardner, H. (2015). Inteligencias múltiples. Barcelona: Paidós.

Garza de la, E. (2018). La metodología configuracionista. México: Gedisa.

Gilar, R., Pozo, T., \& Castejón, J. (2019). Desarrollando la inteligencia emocional en educación superior: evaluación de la efectividad de un 
programa en tres países. Educación XX1, 22(1), 161-187. https://doi. org/10.5944/educXX1.19880

Goleman, D. (2016). La inteligencia emocional. México: Ediciones B.

Han, B. (2017). Psicopolítica. Barcelona: Herder.

Hanhela, T. (2014). Axel Honneth's idea of a drawn-out process of education. Pedagogy, Culture \& Society, 22(3), 369-388. Recuperado de http://bit.ly/2znjqqH

Heller, A. (1977). Sociología de la vida cotidiana. Barcelona: Península.

Heller, A. (1993). Teoría de los sentimientos. México: Fontamara.

Ibarra, L. (2017a). ¿Cómo educar?. Revista Educarnos, 6(24-25), 11-38. Recuperado de https://goo.gl/pqup8C

Ibarra, L. (2017b). Afectividad, educación y utopía. Una perspectiva socioantropológica. Saberes y prácticas. Revista de Filosofía y Educación, 2, 1-22. Recuperado de http://bit.ly/31v1cR3

Mayer, J., DiPaolo, M., \& Salovey, P. (1990). Percerving affective content in ambiguous visual stimuli: A component of emotional intelligence. Journal of Personality Assessment, 54, 772-781. Recuperado de http://bit.ly/2MEFWE3

Monsalve, N., \& Monsalve, C. (2015). La inclusión de la computadora en el aula por docentes de quinto grado de básica primaria como herramienta para propiciar el aprendizaje significativo en estudiantes. Revista Escuela de Administración de Negocios, (79), 50-63. Recuperado de http://bit.ly/2KW9JpS

Morin, E. (1998). Introducción al pensamiento complejo. Barcelona: Gedisa.

Neisser, U. (1999). Psicología cognoscitiva. México: Trillas.

Nieto, M., Barrios, M., \& Extremera, N. (2019). Autoeficacia de búsqueda como mediadora de la inteligencia emocional y la búsqueda activa de empleo. Revista de Psicología Social, 34(1), 86-109.

Ocampo, J. (2019). Sobre lo "neuro" en la neuroeducación: de la psicologización a la neurologización de la escuela. Sophia, Colección de Filosofía de la Educación, (26), 141-169. Recuperado de http://bit. ly/2ZsOGTS 
Ortiz, A. (2017). Configuración epistémica de la pedagogía. Tendencias que han proliferado en la historia de la educación. Revista Historia de la Educación Latinoamericana, 19(29), 165-195. Recuperado de http:// bit.ly/2zlOZ4c

Paterno, R. (2014). Luces y penumbras de la neuroeducación. Revista Iberoamericana de Psicomotricidad y Técnicas Corporales, (39), 122-127. Recuperado de http://bit.ly/2ZuKor8

Prieto, M. (2018). La psicologización de la educación: Implicaciones pedagógicas de la inteligencia emocional y la psicología positiva. Educación XX1, 21(1), 303-320. https://doi.org/10.5944/ educXX1.16058

Rueda, P., \& Filella, G. (2016). Importancia de la educación emocional en la formación inicial del profesorado. Intercambio/Échange, 1(18), 212-219. https://doi.org/10.21001/ie.2016.1.17

Sánchez, M. (2017). Agentes humanos, ficciones, homúnculos: en defensa de un enfoque no homuncular de la agencia. Metafísica y persona. Filosofía, conocimiento y vida, 9(18), 61-79. Recuperado de http:// bit.ly/3418fSI

Solís, V. (2014). La psicología cognoscitiva: ejemplo eminente de interdisciplina. Ludus Vitalis, 22(41), 279-287. Recuperado de http://bit.ly/2ZgmJzj

Varas-Genestier, P., \& Ferreira, R. (2017). Neuromitos de los profesores chilenos: orígenes y predictores. Revista Estudios Pedagógicos, 43(3), 341-360. Recuperado de http://bit.ly/2NAn1ds

Weber, M. (2004). El político y el científico. México: Colofón.

Zamudio, A., \& Castorina, J. (2016). La cuestión del a priori: de Kant a Piaget. Schème. Revista Electrônica de Psicologia e Epistemologia Genéticas, 8(2), 4-27. Recuperado de http://bit.ly/2HsuZkL 